\title{
CRESCIMENTO URBANO DO MUNICÍPIO DO IGACI-AL E PERDA DA QUALIDADE DE VIDA
}

\author{
Felippe Pessoa de Melo ${ }^{1}$
}

\begin{abstract}
RESUMO: O sítio urbano do município do Igaci-Al está crescendo de forma insustentável, em direção a suas áreas de encostas. A população que ocupa essa nova área urbana é de baixa renda, logo suas residências são precárias de infraestrutura, situação que se agrava no período chuvoso. Para compreender e fornecer subsídios às políticas públicas foi realizada uma análise das inter-relações entre o modelo de uso e ocupação desse espaço geográfico e suas consequências socioambientais. Tendo como auxílio às tecnologias do Sensoriamento Remoto e Sistemas de Informações Geográficas. Diagnosticou-se que o processo de ocupação das áreas de encostas está desestruturando essas feições do relevo e colocando em risco tanto a população que a ocupa como as demais moradias que estão sob essa área, devido à magnitude que os movimentos de massas podem alcançar. Pois a área apresenta um alto índice declividade.
\end{abstract}

Palavras-chave: Insustentável, socioambientais e tecnologias.

\section{URBAN GROWTH IGACI-AL MUNICIPALITY AND LOSS OF QUALITY OF LIFE}

\begin{abstract}
The urban site of Al-Igaci the city is growing unsustainably, toward their areas of slopes. The population that occupies this new urban area is poor, then their homes are poor infrastructure, a situation that worsens during the rainy season. To understand and provide subsidies to public policy was an analysis of the interrelations between the model of use and occupation of geographic space and its social and environmental consequences. With the aid of technologies of Remote Sensing and Geographic Information Systems. Was diagnosed that the process of occupation of hillsides is disrupting these features relief and endangering both the population that occupies as the other houses that are under this area, due to the magnitude that the mass movements can achieve. Because the area has a high rate slope.
\end{abstract}

Keywords: Unbearable, social, environmental and technologies.

\footnotetext{
${ }^{1}$ Mestre em Geociências e Análise de Bacias Sedimentares pela Universidade Federal de Sergipe, Professor efetivo das Redes Estadual de Alagoas e Municipal de Garanhuns-PE e Tutor da Universidade Federal de Sergipe. felippemelo@hotmail.com
} 


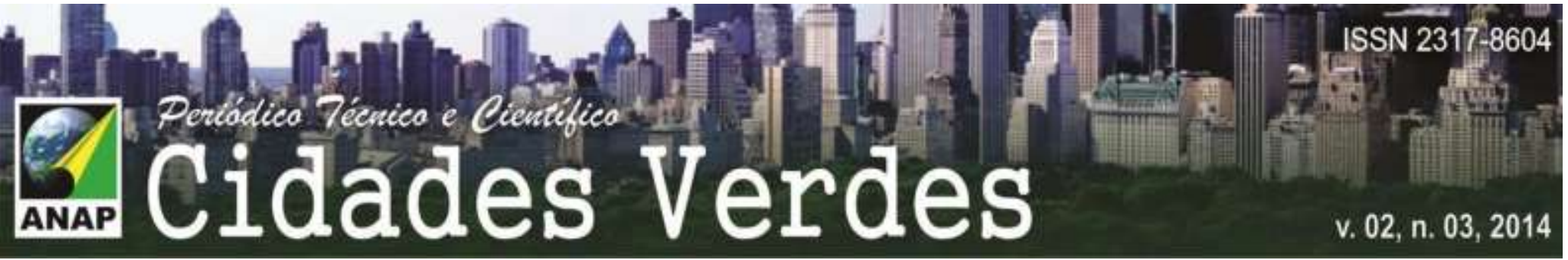

\section{CRECIMIENTO URBANO IGACI-AL MUNICIPIO Y PÉRDIDA DE LA CALIDAD DE VIDA}

\section{RESUMEN}

O sítio urbano del Municipio hacer Igaci-Al this crescendo de forma insustentável, em direção un suas áreas de Encostas. Un população Que OCUPA essa nova área urbana é de baixa renda, logotipo suas Residencias são Precarias de infraestrutura, Situación Que se Agrava no chuvoso período m. Para compreender e fornecer SUBSIDIOS às Políticas Públicas foi uma análise das Realizada entre Relações Entre o modelo de la USO e ocupação desse Espaço geográfico e suas consequências socioambientais. Tendo Como auxílio às tecnologias hacer Sensoriamento Remoto e Sistemas de Informaciones Geográficas. Diagnosticou-se que o processo de ocupação das áreas de Encostas this desestruturando Essas feições hacen RELEVO e colocando em risco del tanto un população Que un OCUPA Como ya demais moradias Que Estão área essa sollozo, devido à magnitud Que os movimentos de massas podem alcançar. Pois un área apresenta um alto índice declividade.

PALABRAS-CLAVE: Insustentável, socioambientais y Tecnologías.

\section{INTRODUÇÃO}

Devido sua proximidade a Arapiraca $(28 \mathrm{~km})$ e Palmeira dos Índios $(16 \mathrm{Km})$, suas terras apresentam um alto valor comercial. Com a Inauguração do Campus III da Universidade Estadual de Alagoas em 2009 na AL 115, Km 03 e a expansão urbana de Arapiraca, os lotes no Igaci maximizaram ainda mais seus valores.

Tendo como consequência direta a redução das áreas rurais e ampliação do perímetro urbano. Esse novo modelo de uso e ocupação do solo, não está levando em conta que os pequenos produtores que migram do campo em direção ao centro urbano do município do Igaci não têm condições financeiras para comprarem residências adequadas para sua fixação. Com isso são forçados a ocuparem áreas íngremes do modelado.

Com a retirada da vegetação nativa para implantação de submoradias, desestabiliza o modelado, maximizando a susceptibilidade aos agentes erosivos. $\mathrm{Na}$ área em questão destaca-se a ação das águas no período chuvoso, provocando deslizamentos e desmoronamentos.

Essa dinâmica socioespacial transcende esse novo perímetro urbano, pois em seu sopé passa a Al 115 e existem outros polígonos residências sob essa rodovia. Dessa 
forma observa-se que outros segmentos da sociedade estão sendo colocados em risco devido à insustentabilidade desse fenômeno urbanístico.

\section{MATERIAIS E MÉTODOS}

\subsection{MATERIAIS}

Para a realização da pesquisa, os materiais foram empregados conforme a necessidade de cada método aplicado. Portanto utilizou-se: material bibliográfico que contemplasse a problemática socioambiental da área em questão; Dados SRTM, do projeto Brasil em Relevo da EMBRAPA, com as seguintes características técnicas: formato GeoTiff / 16 bits, resolução espacial de 90m, sistema de coordenadas geográficas e datum WGS-84, correspondente à carta digital SC-24-X-D; Imagens via satélite da DGI do INPE, obtidas através dos satélites: Landsat 5 equipado com o sensor TM que apresenta a resolução espacial de 30m. As imagens são referentes aos anos: 1990 e 2010 e CBERS 2B, equipado com o sensor HRC que possui uma resolução espacial de 2,7m, referentes aos anos de 2009 e 2010; Arquivos vetoriais da CPRM, arquivos shp e PDF, do IBGE; GPS e os SIGs ArcGIS 10.1, QGIS 1.8, Global Mapper 13.0, QGIS 1.8 e SPRING 2.2.

\subsection{MÉTODOS}

Foi criado um banco de dados geográficos georreferenciado contendo as informações provenientes da pesquisa de gabinete.

Posteriormente foi realizada uma pesquisa de campo, com a finalidade de confirmar, corrigir e reambular as informações provenientes da pesquisa de gabinete.

Em seguida realizou-se as análises e interpretações do material para posterior confecção das cartas temáticas.

\section{CARACTERIZAÇÃo DA ÁREA}




\section{Pentódica Técrica e Cuntéfica}

A cidade do Igaci está localizado na porção central de Alagoas, é cortado pela AL 115, está á $146 \mathrm{Km}$ de distância em relação a Maceió. Faz divisa com as cidades de: Arapiraca, Belém, Cacimbinhas, Coité do Nóia, Craíbas, Estrela de Alagoas, Major Isidoro, Palmeira dos índios e Taquarana (Figura 01).

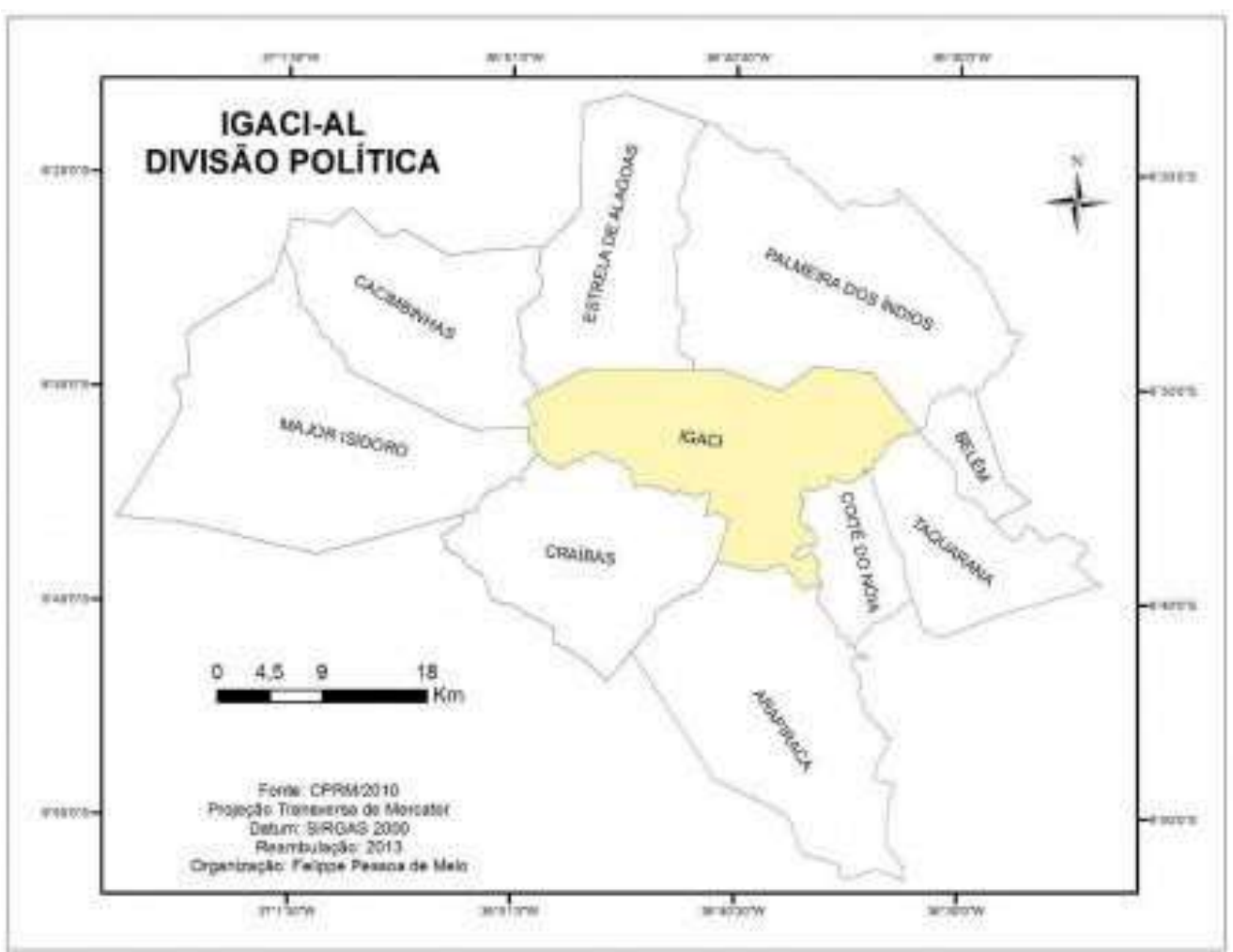

Figura 01 - Localização espacial do Igaci-Al e cidades circunvizinhas.

\subsection{ASPECTOS FISIOGRÁFICOS}

O município e adjacênicas apresentam valores hipsométricos que vão de 140 a $531 \mathrm{~m}$ (Figura 02), sua altimetria está distribuída de forma bem distinta na paisagem (Tabela 01).

\begin{tabular}{|c|c|c|c|c|c|}
\hline Altimetria & Área $\left(\mathrm{Km}^{2}\right)$ & Percentual (\%) & Altimetria & Área $\left(\mathrm{Km}^{2}\right)$ & Percentual (\%) \\
\hline $140-188$ & 0,91 & 0,27 & $335-384$ & 3,21 & 0,95 \\
\hline $188-237$ & 108,42 & 32,39 & $384-433$ & 1,47 & 0,43 \\
\hline $237-286$ & 188,82 & 56,41 & $433-482$ & 0,5 & 0,14 \\
\hline $286-335$ & 31,10 & 9,29 & $482-531$ & 0,26 & 0.07 \\
\hline
\end{tabular}



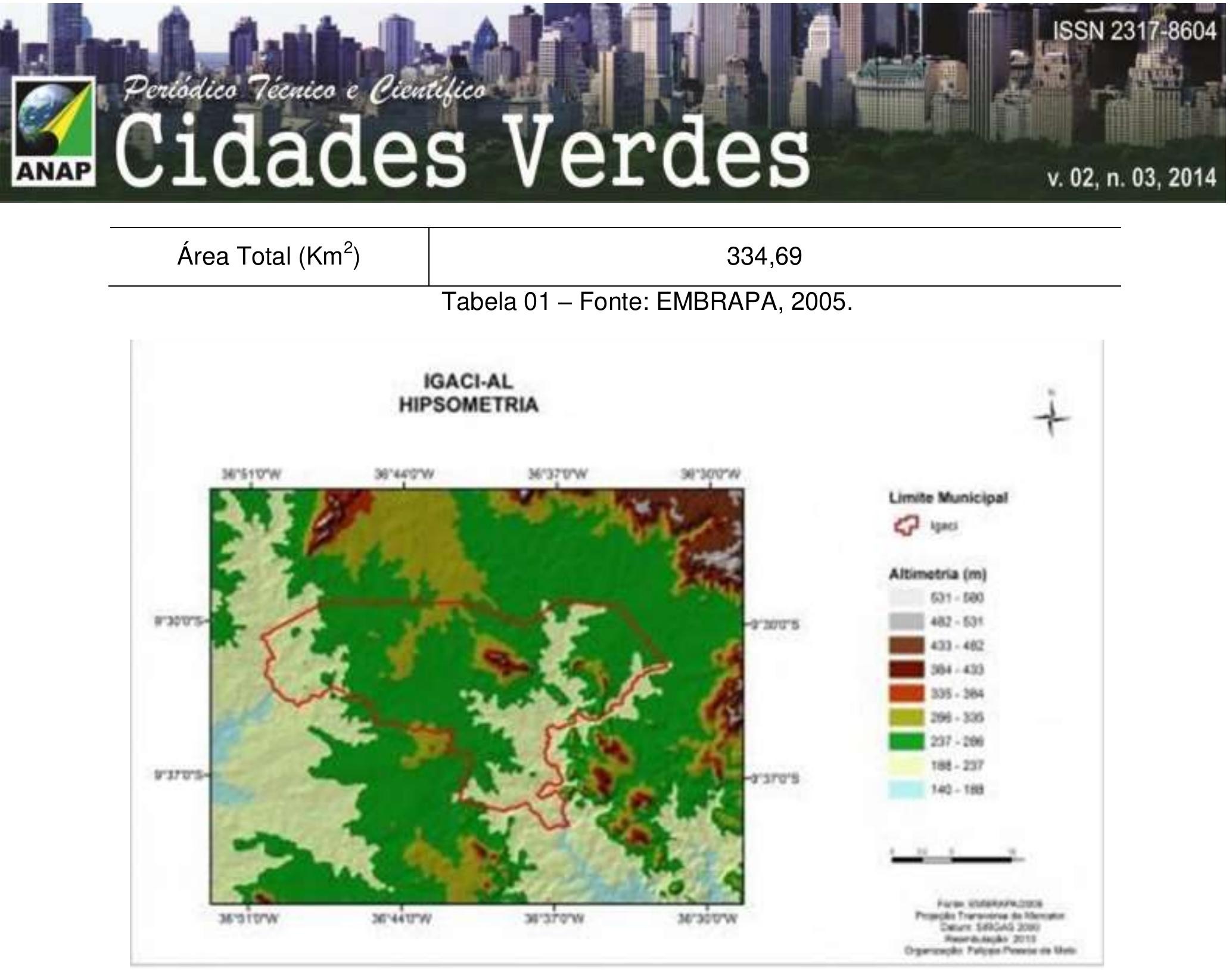

Figura 02 - Características topográficas.

A cota altimétrica a partir de $531 \mathrm{~m}$ mais próxima do perímetro do município está a $6.800 \mathrm{~m}$ do limite noroeste (Figura 03). 

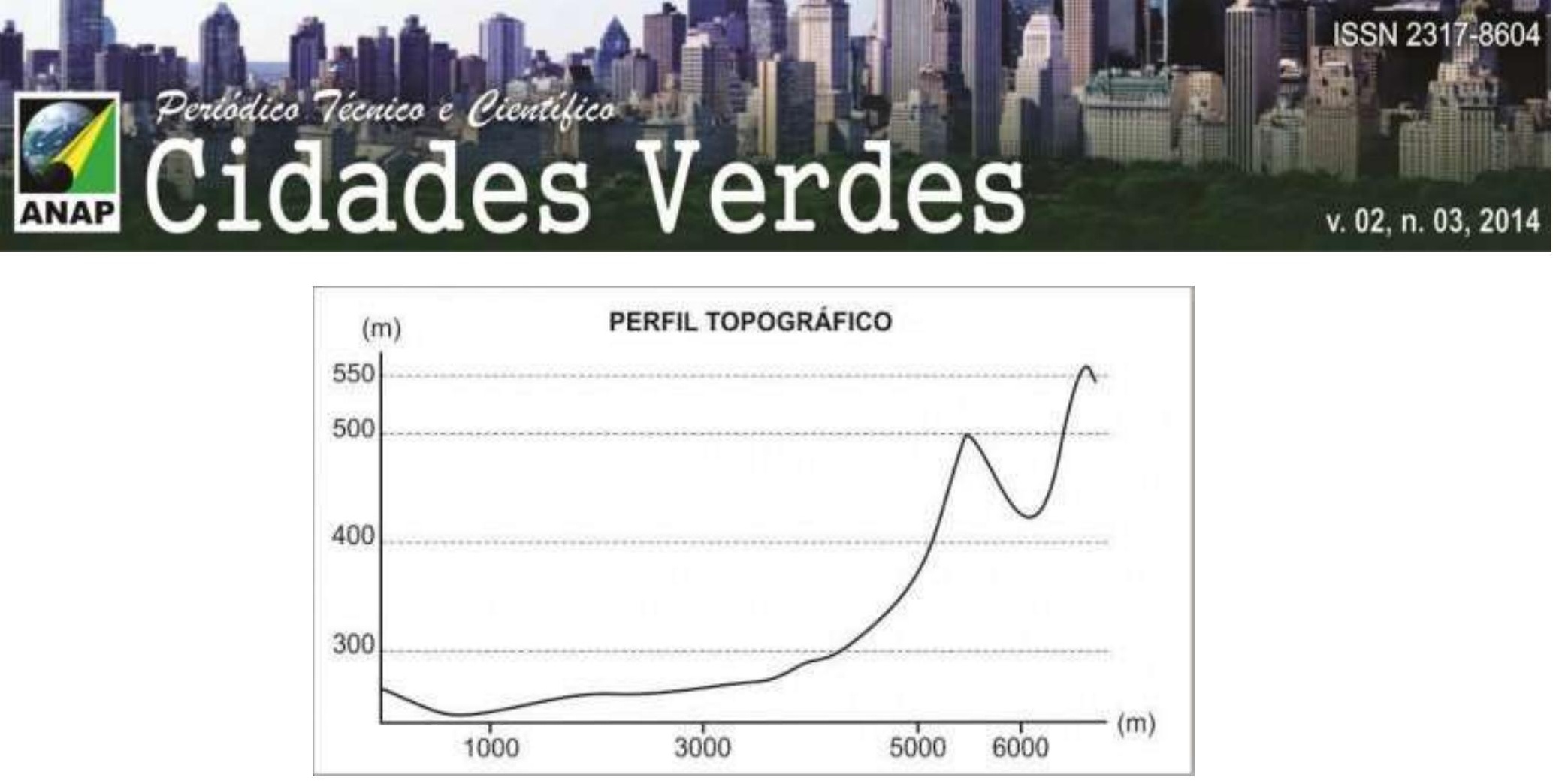

Figura 03 - Cota altimétrica a partir de 531m mais próxima.

O município está sob os domínios dos climas semiárido e semiúmido (Figura 04), o primeiro ocupa uma área de $86,70 \%$ do território. O segundo ocorre na porção nordeste, ocupando o resto do perímetro, ou seja, $13,3 \%$ da área. Nas proximidades dos limites municipais, a nordeste encontra-se a presença do clima úmido.

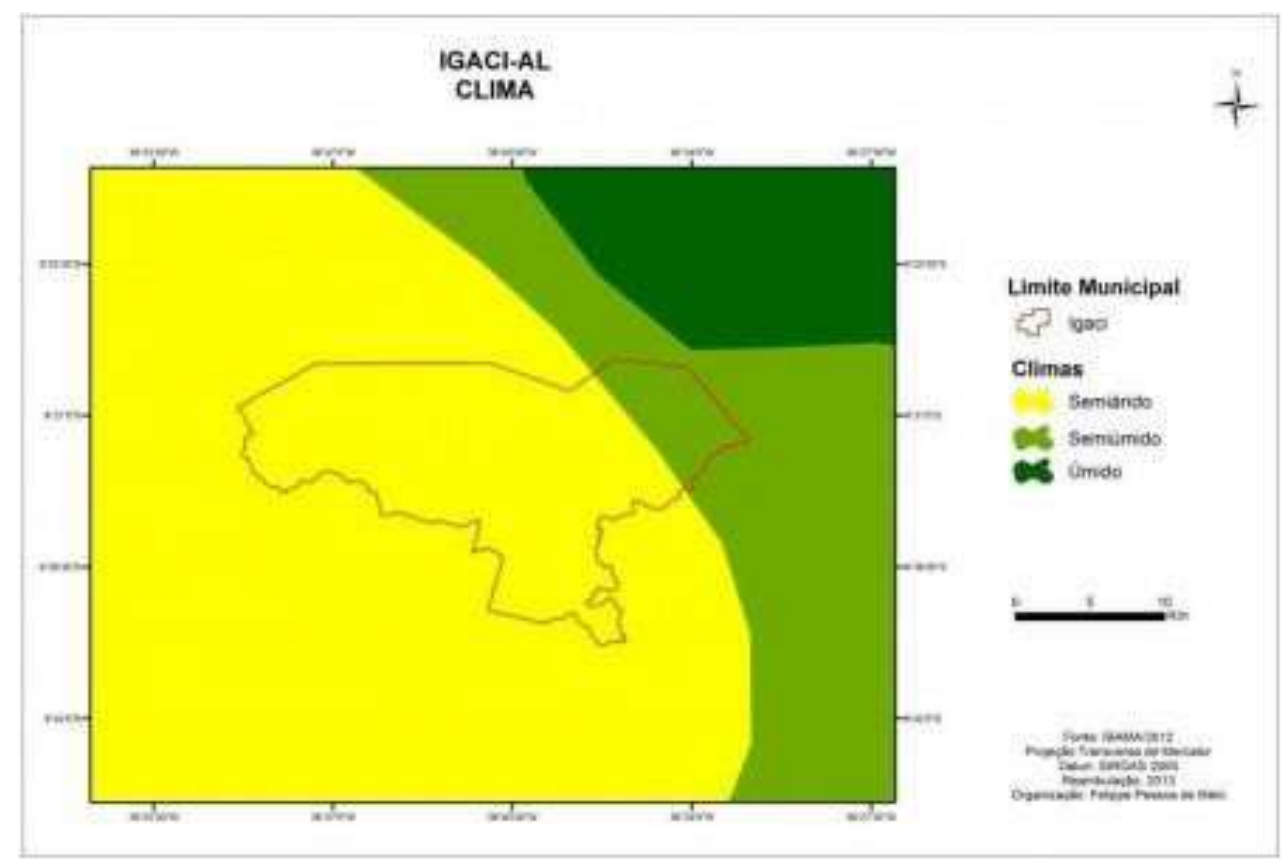

Figura 04 - Sistemas climáticos. 

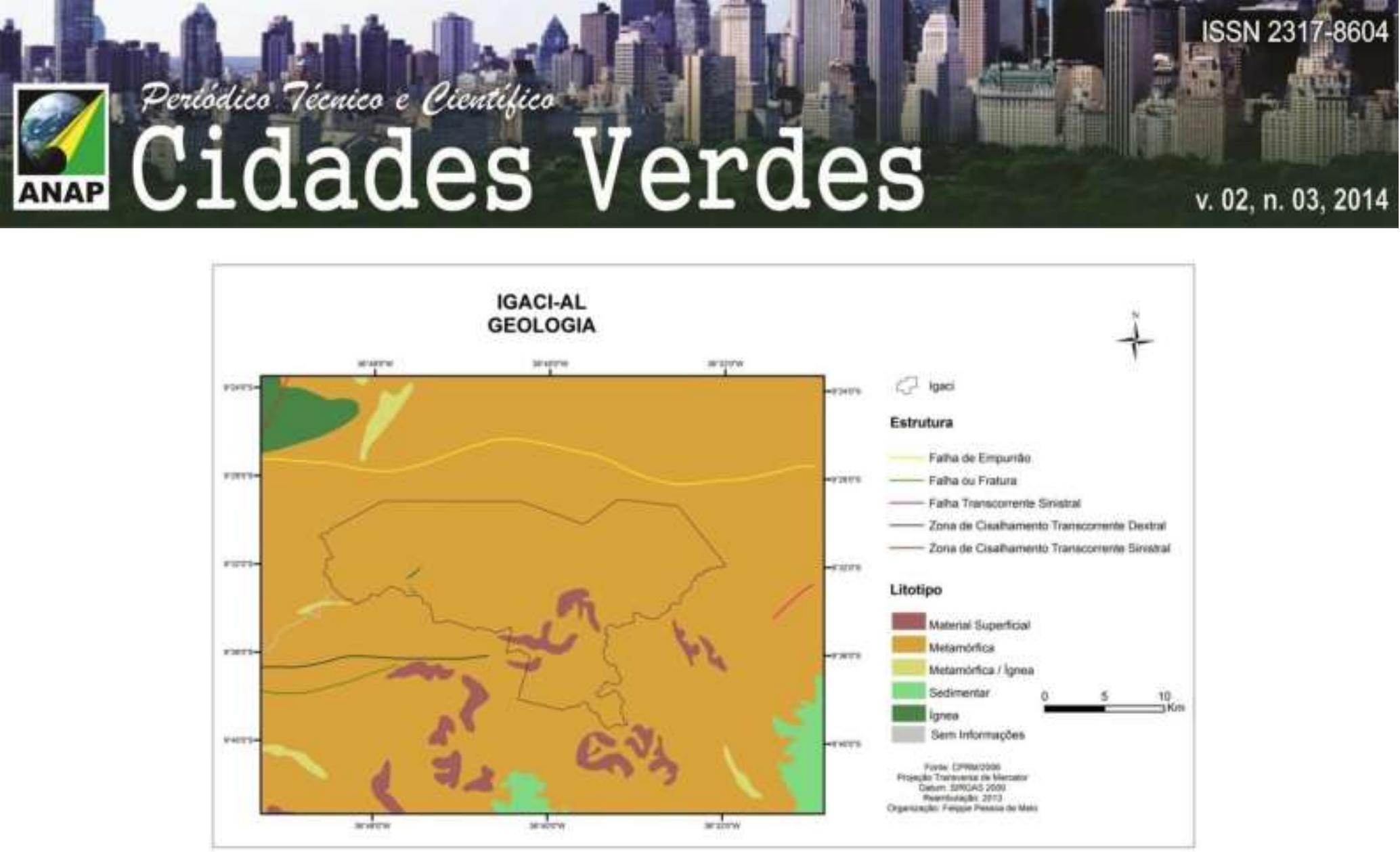

Figura 09 - Estrutura geológica.

\subsection{HIDROGRAFIA}

O município faz parte da bacia hidrográfica do Rio São Francisco, sendo banhado pela sub-bacia do Rio Coruripe, o qual tem sua nascente em Palmeira dos Índios-Al e atravessa o Igaci-Al nas porções nordeste / sudoeste (Figura 10). Sendo que os demais cursos de águas desempenham um importante papel nas atividades agrárias do município. 

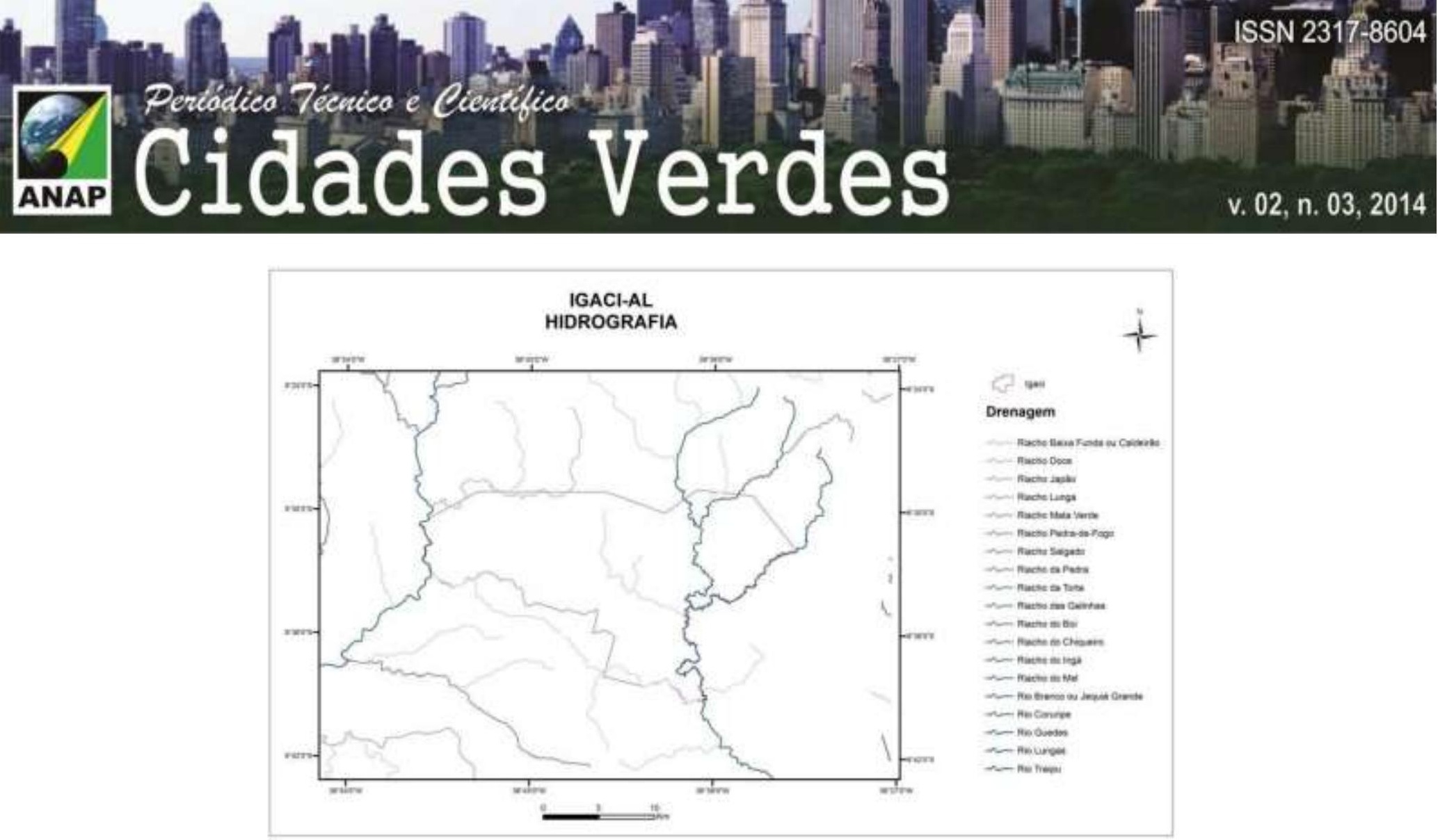

Figura 10 - Drenagem.

\section{USO E OCUPAÇÃO DO SOLO}

\subsection{RETIRADA DA COBERTURA VEGETAL E CONSEQUÊNCIAS GEOAMBIENTAIS}

A nova lógica ou modelo de uso e ocupação do espaço geográfico do Igaci-AL, não está levando em consideração que o ex-produtor agrícola ao implantasse no sítio urbano, não tem condições financeiras de comprar uma residência ou terreno em um local adequado.

Dessa forma essas famílias começam o processo de desmatamento da cobertura vegetal das feições íngremes do modelado (Figura 11) para práticas agrárias de subsistência insustentáveis e fixação de moradias precárias (Figura 12). 

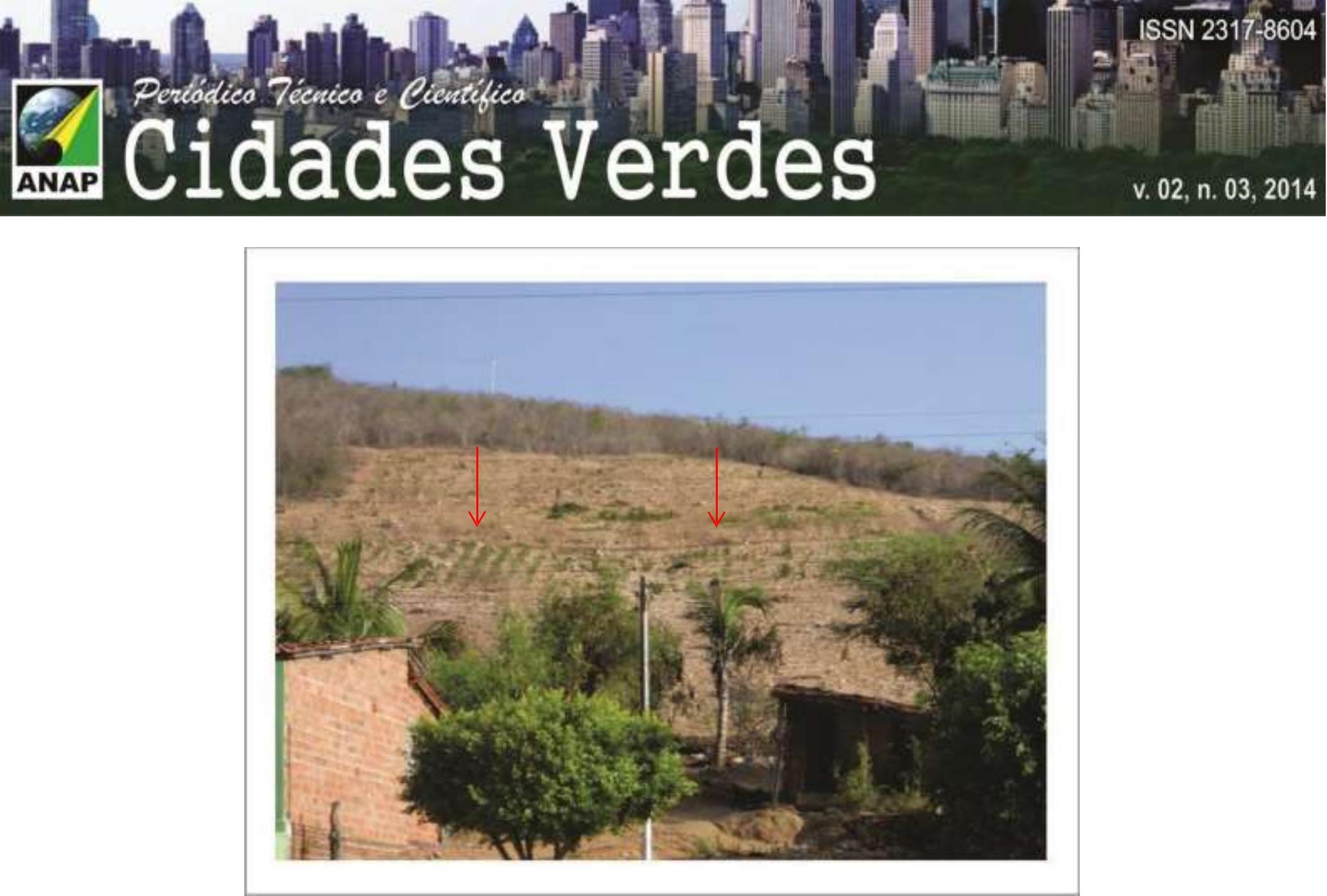

Figura 11 - Agricultura familiar.

Tendo com consequências quase que imediatas: desestabilização das encostas, lixiviamento dos solos, deslizamentos, contaminação e assoreamento dos corpos de d'águas, proliferação de doenças de veiculação hídrica... é necessário ressaltar que o modelado do município naturalmente já é bem susceptível a movimentos de massas devido suas peculiaridades topográficas.

Dessa forma a preservação da flora nessas encostas é de suma importância para que ocorra o ecoequilíbrio. Proporcionando assim o aumento da qualidade de vida da população. 

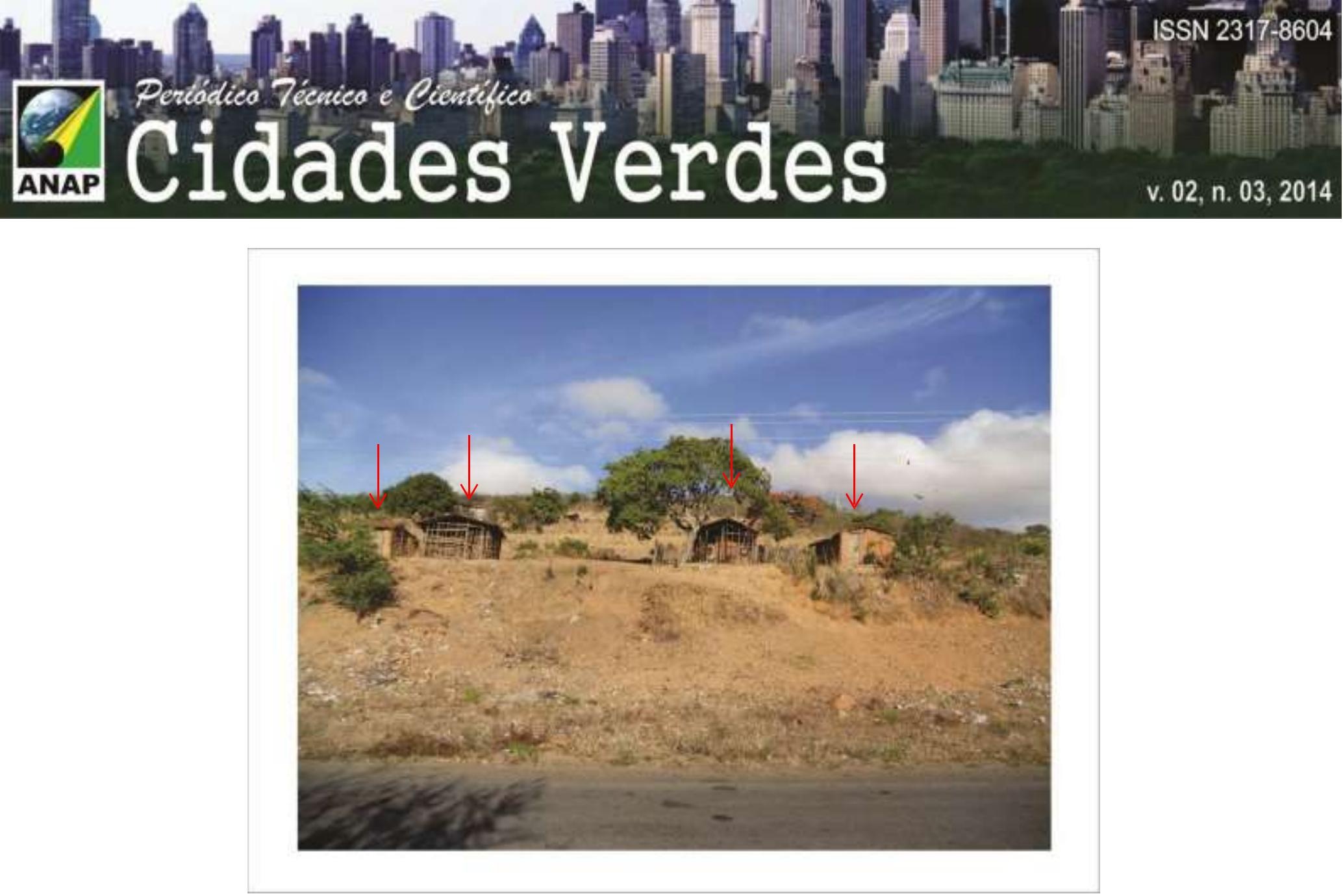

Figura 12 - Casas de pau-a-pique.

Contudo faz-se necessário salientar que esses novos habitantes urbanos não podem ser responsabilizados por esse cenário ambientalmente e socialmente instável. Logo eles são, nada mais nada a menos que o reflexo de processos de especulações imobiliárias e de políticas públicas equivocadas.

Portanto cabe à sociedade de forma geral traçar metas plausíveis para reimplantação desses habitantes em um local adequado e dar condições que os mesmos possam desenvolver atividades econômicas capazes de manter suas famílias de forma digna. Pois a simples remoção desses habitantes para outra localidade apenas transferirá o problema de local.

\section{2 ÁREAS DE RISCO PARA OCUPAÇÃO ANTRÓPICA}

O sítio Urbano do Igaci-Al possui uma área de $0,97 \mathrm{Km}^{2}$, dos quais $3 \%$ estão em locais de baixo risco, $71 \%$ encontram-se em áreas de médio risco e $26 \%$ estão em áreas de elevado risco (Figura 13). Para agravar 


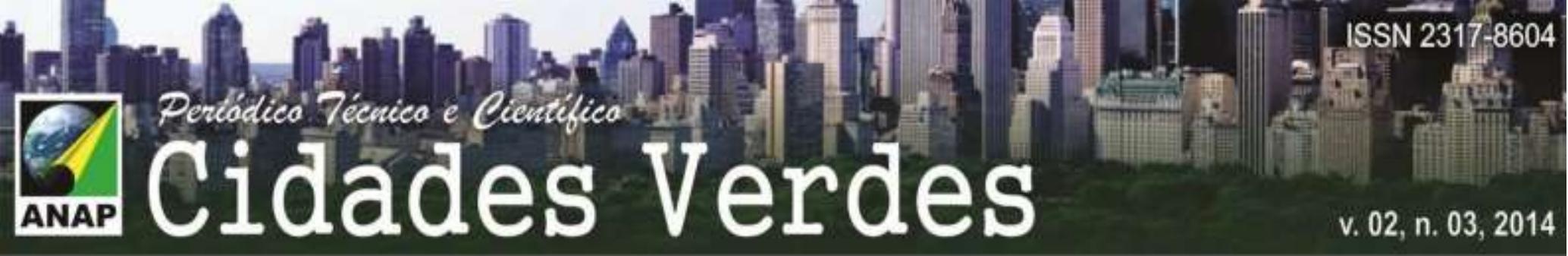

ainda mais a situação um trecho da $\mathrm{Al} 115$, passa pela área considerada de alto risco, 0 que coloca em risco os passageiros dos veículos que passam por essa rota.

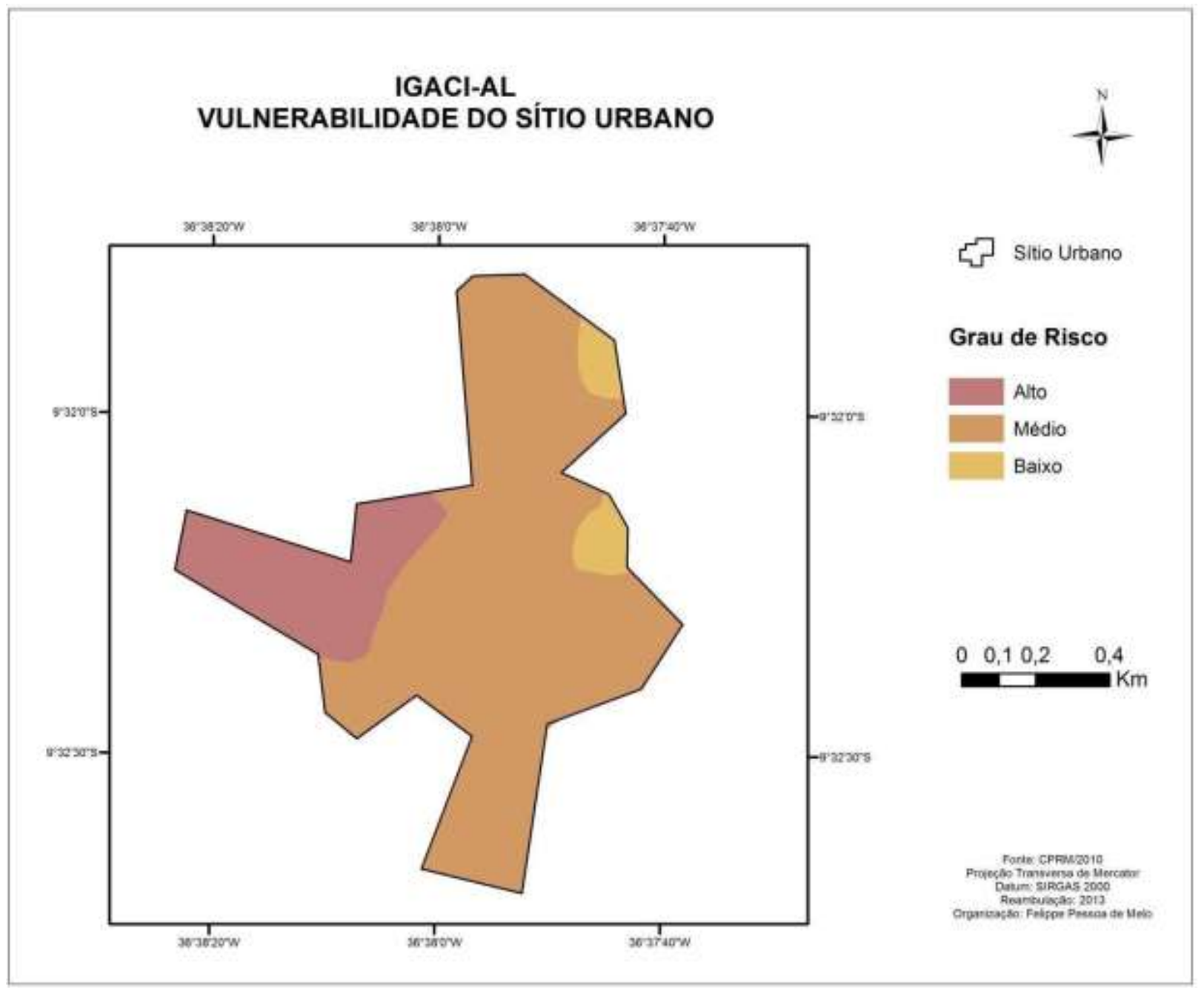

Figura 13 - Susceptibilidade a movimentos de massas.

Com base nos dados constata-se que o território igaciense está situado em um cenário geoambiental instável. Para minimizar essa situação faz-se necessário a implantação de um plano gestor municipal que trace metas de desenvolvimento que contemplem os princípios da sustentabilidade.

Deve-se ressaltar que essas áreas já estão com altos índices de ocupação, portanto, a remoção populacional fica inviável devido aos altos custos para os cofres públicos.

Dessa forma uma alternativa viável para minimizar os impactos causados pela urbanização é a preservação das coberturas vegetais urbanas remanescentes. Já que 


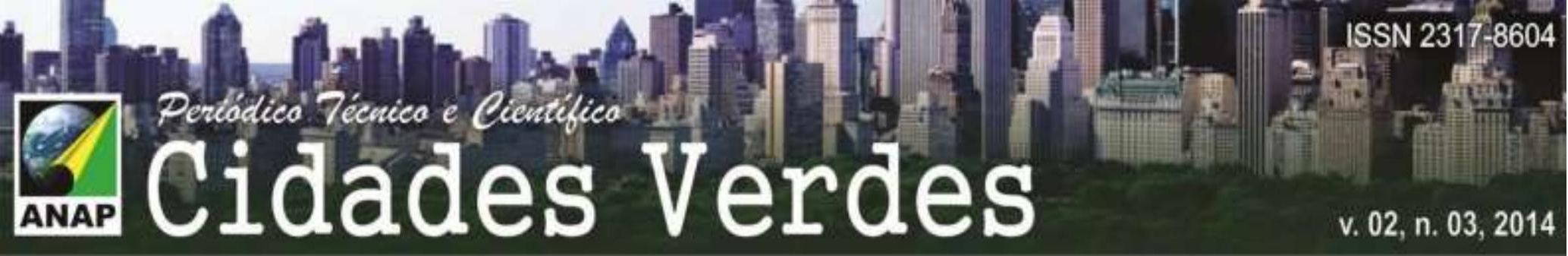

essas áreas estão começando a ser ocupadas pela população, sua retirada para outros locais mais adequados minimizariam problemas como: fluxos de massas constantes no período chuvoso em direção as áreas urbanas que se encontram sob as vertentes, perda de solo, diminuição da fauna, invasão de insetos nas residências, perda da qualidade das águas, doenças de veiculação hídrica...

A próxima etapa seria o tratamento adequado dos resíduos residenciais, logo 0 presente município não apresenta saneamento ambiental adequado (Figura 14), sendo possível encontrar fluxos de esgotos urbanos desaguando nas redes hidrográficas locais.

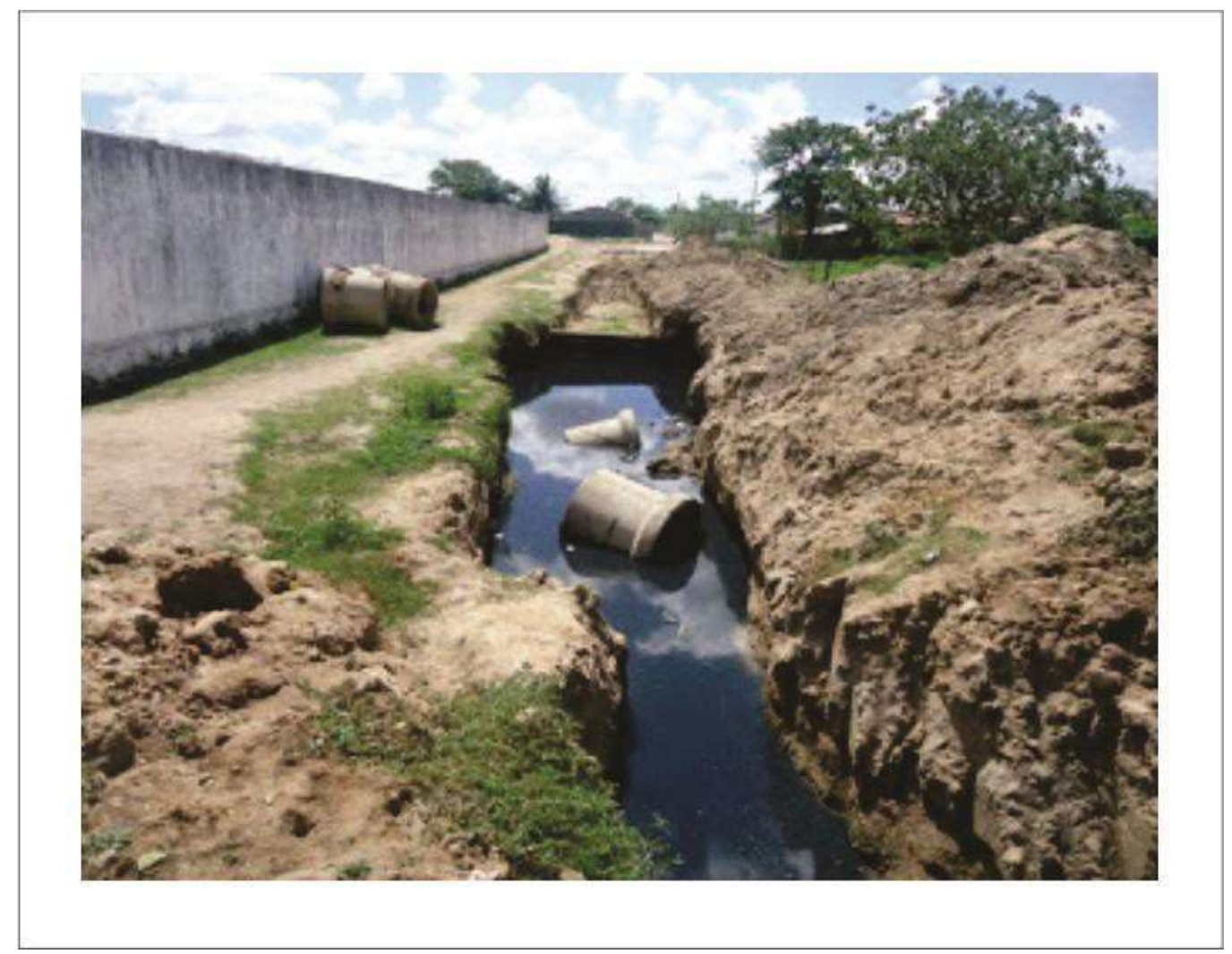

Figura 14 - Sistema de esgoto inadequado.

Em relação aos resíduos sólidos a situação é alarmante, todo o material descartado pelas residências é colocado na paisagem sem o devido tratamento (Figura 15), colocando em risco a saúde da população.

Nos dias ensolarados o cheiro emitido pela matéria orgânica em decomposição dificulta tarefas simples como uma refeição algo quase impossível devido ao mau cheiro. Nos períodos chuvosos os odores diminuem, mas as águas transportam esse material 


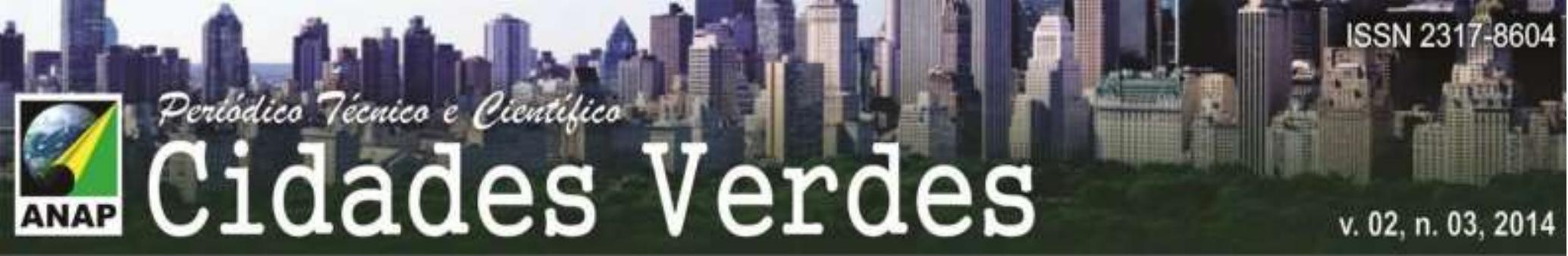

para os córregos dos rios, lagos e facilita a infiltração de materiais pesados no subsolo. Geralmente são oriundos de baterias de: celulares, carros, motocicletas...

E já que a população local tem o hábito de utilizar águas de poços artesianos para consumo humano e animal. Pode ocorre uma série de problemas para saúde humana, tanto pela ingestão da água contaminada como pelo consumo de derivados desses animais.

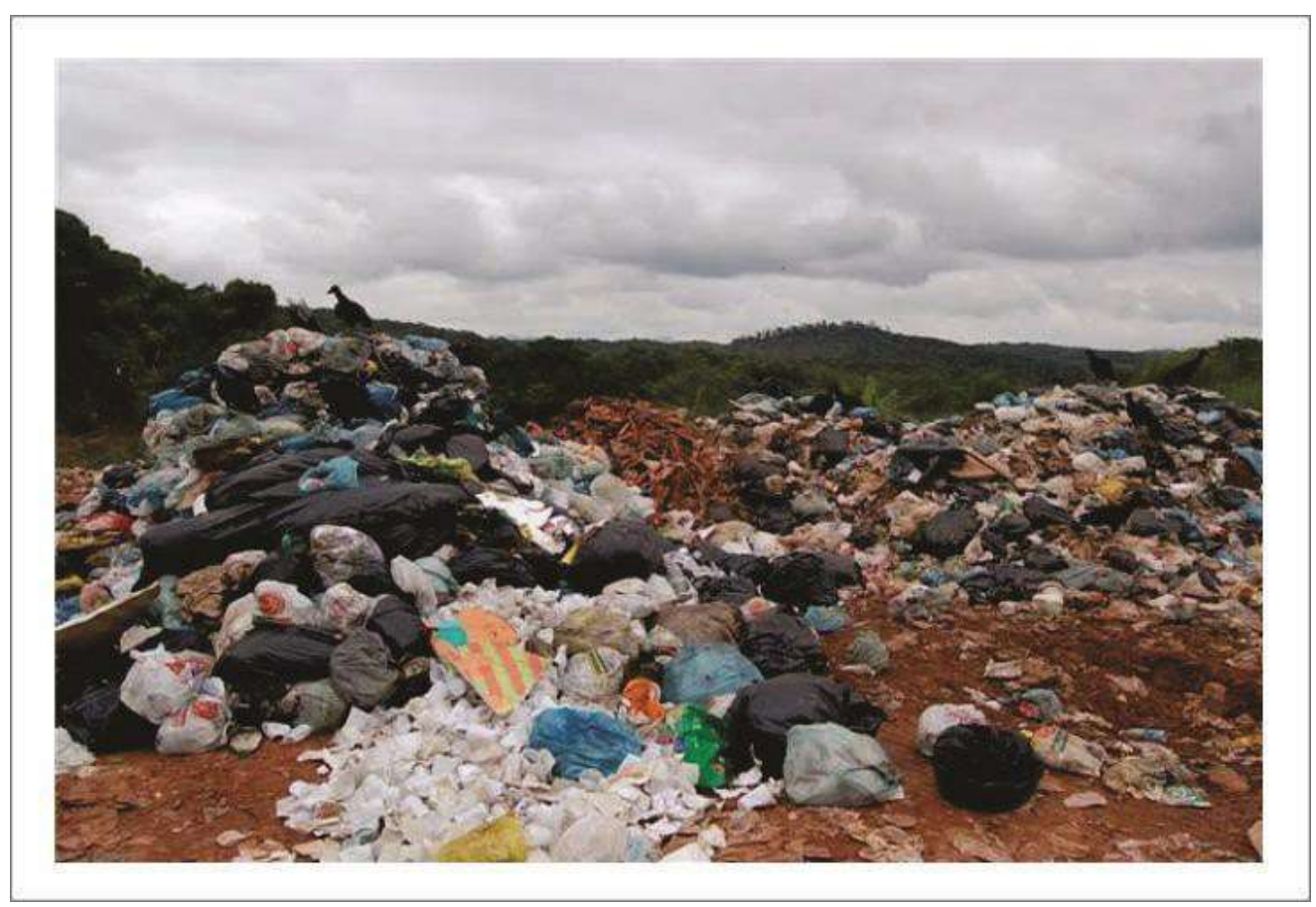

Figura 15 - Descarte de resíduos sólidos.

Essa metamorfose espacial que o Igaci-Al está passando e as consequências ambientais e sociais que elas estão provocando. Só reforçam que nem sempre maximização de áreas urbanas significa melhoria da qualidade de vida da população.

E necessário compreender que melhoria social não significa redução de áreas agrícolas, ampliação do sitio urbano ou verticalização.

\section{3 ÁREAS DE PROTEÇÃO PERMANENTES}

O município não está em consonância com o código florestal, as áreas que deveriam ser destinadas a APPs, são utilizadas para atividades agrárias extensivas. Em relação aos corpos d'água a rede de drenagem localizada dentro do perímetro do Igaci-Al, 


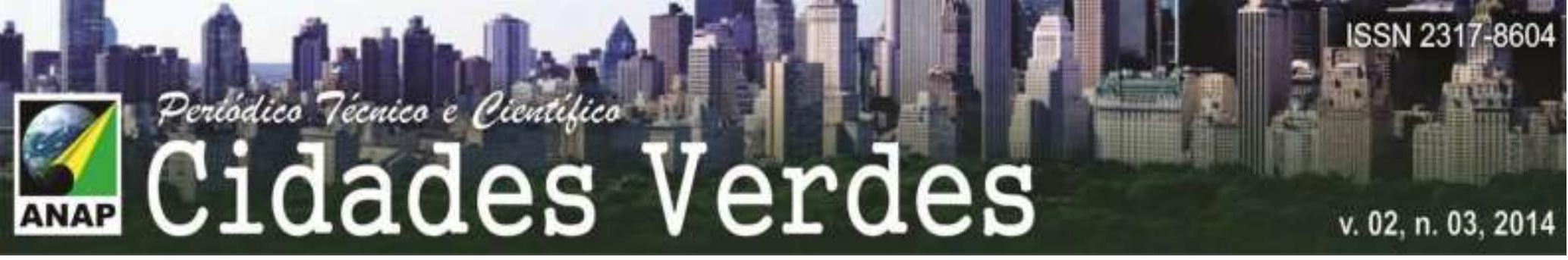

não ultrapassa os $10 \mathrm{~m}$ de comprimento, dessa forma teria que apresentar uma área de preservação permanente $15 \mathrm{~m}$ em cada margem durante todo o seu percurso de $30 \mathrm{~m}$. Que nesse caso específico totalizaria uma área de $5,75 \mathrm{Km}^{2}$. Mas no transcorrer dos cursos das águas só encontram-se resquícios da cobertura vegetal primária.

Em relação aos dois lagos situados dentro dos limites municipais, o problema se repete. Ambos os corpos d'água estão localizados em áreas rurais, dessa forma teriam que possuir uma área de preservação permanente de $100 \mathrm{~m}$ ao redor de suas margens, 0 que corresponderia a $1,74 \mathrm{Km}^{2}$, mas isso não ocorre.

O intenso processo de exploração dos recursos naturais no município pode ser bem evidenciado tomando como exemplo o modelo de uso e ocupação do Lago Jacuípe de Baixo (Figura 16). No qual áreas legalmente protegidas são utilizadas para outros fins.

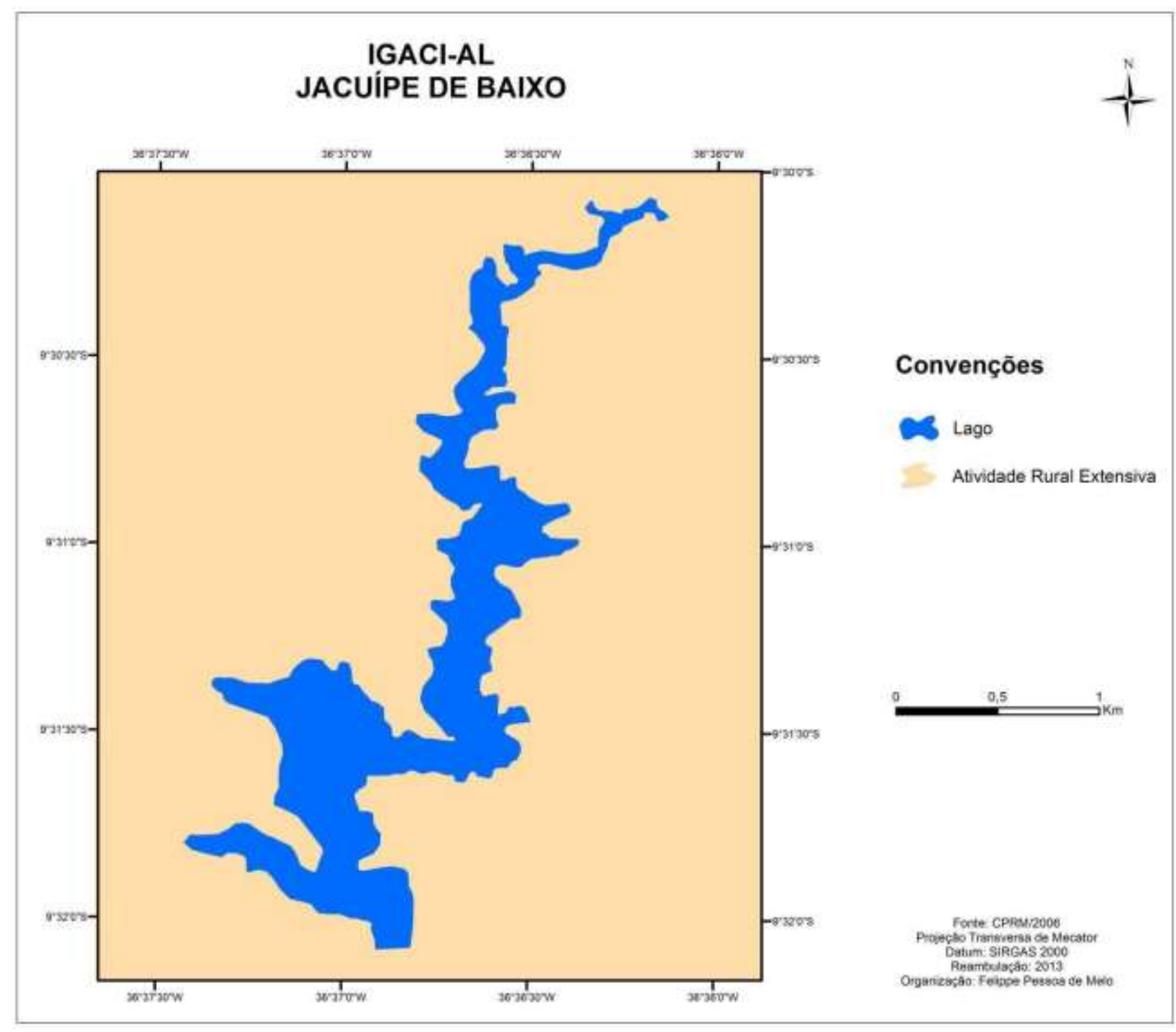

Figura 16 - Uso Inadequado dos recursos naturais. 
Caso o município cumprisse o que é estabelecido na legislação ambiental o cenário ambiental seria outro (Figura 17). A ausência de vegetação nas margens do lago, o torna mais susceptível a processos como: assoreamento, contaminação de suas águas, redução da população de peixes...

O processo de recuperação das margens do Jacuípe de Cima implicaria em um processo de conscientização da população agrícola e urbana. No caso dos habitantes do campo eles desmatam as áreas com cobertura vegetal próxima a corpos d'água para facilitar o acesso humano e animal. Já a população urbana que se localiza nos recôncavos do lago, o utiliza como local de descarte dos resíduos líquidos residenciais.

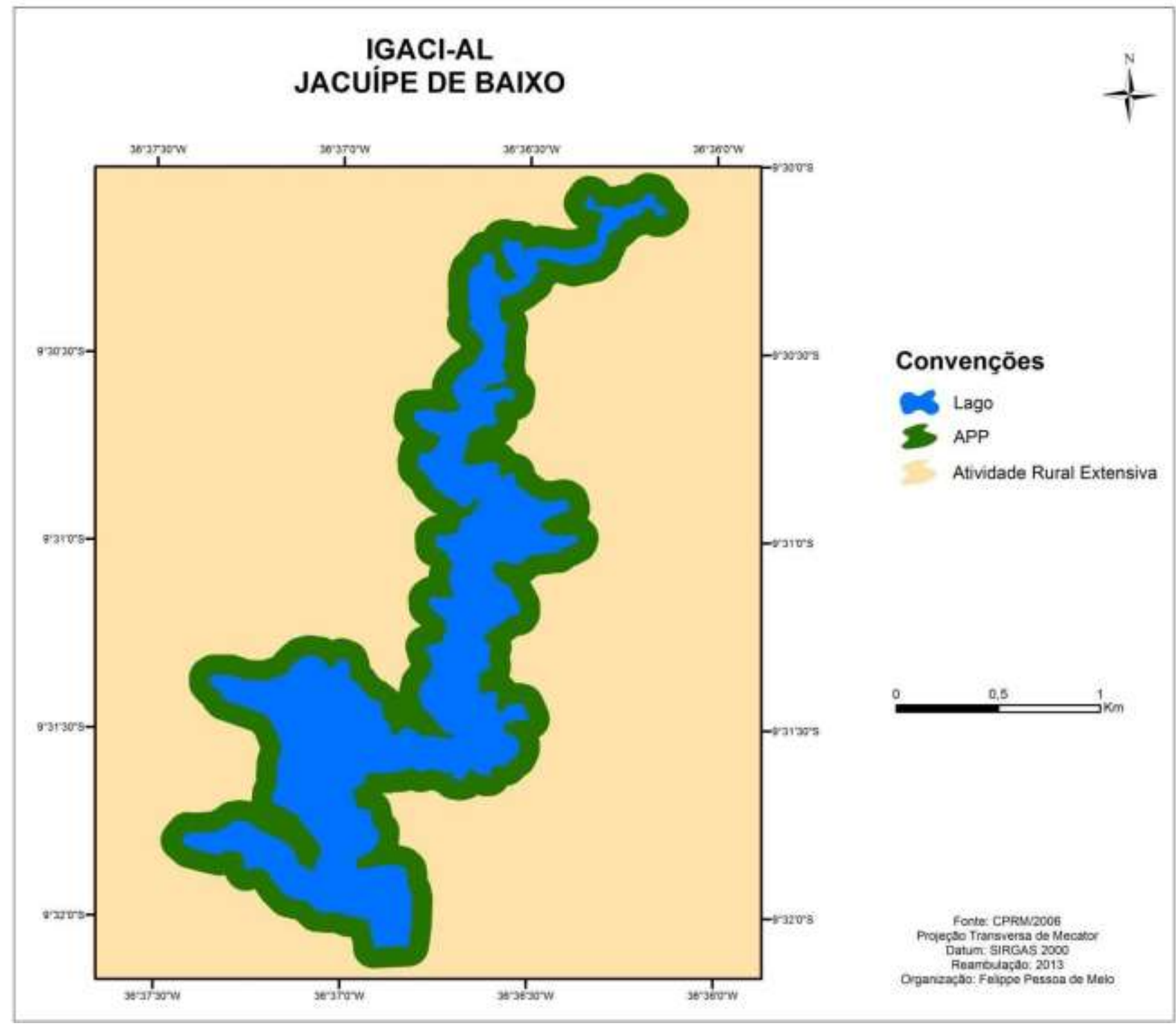

Figura 17 - Uso adequado dos recursos naturais. 


\subsection{RESÍDUOS SÓLIDOS COMO FONTE DE RENDA}

Os habitantes mais carentes utilizam os recursos descartados no lixão público municipal para diversas atividades dentre elas destacam-se: o reaproveitamento de comida estragada para alimentar suínos e coleta de material para reciclagem.

Em relação à coleta dos recicláveis ela ocorre sem as devidas proteções, sendo comum encontrar-se coletores descalços, com as mãos expostas, sem máscaras...

A coleta de matéria orgânica ocorre da mesma forma, porém com um agravante, além dos coletores se contaminarem eles fornecem material contaminado para 0 consumo animal, os quais servirão de alimentos para população.

Essas atividades de coletas são feitas por adultos, idosos e crianças.

É logico que a reciclagem é uma saída viável para gerar renda e minimizar os impactos ambientas. Mas da forma que ela está ocorrendo os malefícios são maiores que os benefícios.

\section{CONCLUSÕES}

Com o auxílio das tecnologias do Sensoriamento Remoto e SIG foi possível confeccionar um banco de dados digitais georreferenciados. O qual subsidiou a confecção das cartas temáticas necessárias para realização das análises e interpretações da dinâmica de uso e ocupação do solo no município do Igaci-Al.

Com base na correlação entre os dados, detectou-se que o processo de expansão urbana está ocorrendo de forma insustentável. De forma que os mais prejudicados são os pequenos produtores rurais que migram em direção ao sítio urbano do Igaci e por falta de recursos instalam-se em áreas inadequadas para fixação de moradias e práticas agrárias de subsistência.

O tratamento dos seus resíduos residenciais é outro grande problema a ser enfrentado. Faz-se necessário que a sociedade igaciense, adote um modelo sustentável de uso e ocupação da paisagem.

E para que isso ocorra o município tem quem traçar um plano diretor que coloque em primeiro plano a seguridade socioambiental. 


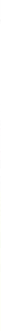

\section{REFERÊNCIAS}

CPRM-Companhia de Pesquisa de Recursos Minerais. Geobank. Disponível em: <http://www.cprm.gov.br/>. Acesso em: 21 de mar. 2013.

EMBRAPA-Empresa Brasileira de Pesquisas Agropecuárias. Projeto Brasil em Relevo. Disponível em: <http://www.relevobr.cnpm.embrapa.br/download/index.htm>. Acesso em: 14 de abr. 2013.

INPE-Instituto Brasileiro de Pesquisas Espaciais. Catálogo de Imagens. Disponível em: <http://www.dgi.inpe.br/CDSR/>. Acesso em: 20 de abr. 2013.

Portal Brasil. Código Florestal. Disponível em: <http://www.brasil.gov.br/sobre/meioambiente/legislacao-e-orgaos/codigo-florestal>. Acesso em: 26 de mar. 2013. 